\title{
JACQUET-FRANCILLON (François), KAMBOUCHNER (Denis) (dir.), La crise de la culture scolaire. Origines, interprétations, perspectives.
}

Paris : Presses universitaires de France, 2005, 505 p.

\section{Annie Bruter}

\section{OpenEdition}

\section{Journals}

Édition électronique

URL : https://journals.openedition.org/histoire-education/615

DOI : 10.4000/histoire-education.615

ISSN : 2102-5452

\section{Éditeur}

ENS Éditions

\section{Édition imprimée}

Date de publication : 1 janvier 2008

Pagination : 143-144

ISBN : 978-2-7342-1113-6

ISSN : 0221-6280

\section{Référence électronique}

Annie Bruter, « JACQUET-FRANCILLON (François), KAMBOUCHNER (Denis) (dir.), La crise de la culture scolaire. Origines, interprétations, perspectives. », Histoire de l'éducation [En ligne], 117 | 2008, mis en ligne le 20 octobre 2008, consulté le 20 mai 2021. URL : http://journals.openedition.org/histoireeducation/615; DOI : https://doi.org/10.4000/histoire-education.615

Ce document a été généré automatiquement le 20 mai 2021.

(C) Tous droits réservés 


\section{JACQUET-FRANCILLON (François), KAMBOUCHNER (Denis) (dir.), La crise de la culture scolaire. Origines, interprétations, perspectives.}

Paris : Presses universitaires de France, 2005, 505 p.

\section{Annie Bruter}

\section{RÉFÉRENCE}

JACQUET-FRANCILLON (François), KAMBOUCHNER (Denis) (dir.), La crise de la culture scolaire. Origines, interprétations, perspectives. Paris : Presses universitaires de France, 2005,505 p.

Ce livre, sans en être les Actes au sens strict, vient à la suite d'un colloque tenu à la Sorbonne du 4 au 6 septembre 2003 sur le thème de la "culture scolaire ", choisi notamment pour rassembler des intervenants relevant de disciplines et d'obédiences diverses. Les directeurs de ce volume assument donc les divergences en son sein, le débat étant «chose positive dès lors qu'il s'agit de s'engager sur la voie de la délibération et de la décision " (p. 10). De fait, il offre un panorama assez large des conceptions historiques des intervenants, parfois fort différentes. C'est ainsi, par exemple, qu'on peut voir affirmer, au début d'une contribution, que «[1]a forme historique que prend un enseignement méthodique et systématique est une organisation disciplinaire de l'enseignement» (p.159), alors qu'une contribution antérieure a décrit l'enseignement des humanités classiques comme non moins méthodique et systématique, quoique non structuré en disciplines. C'est que, si les contributions proprement historiques sont regroupées dans la première partie, intitulée «Histoire et définitions de la culture scolaire», les parties suivantes ne peuvent faire l'économie d'une conception du passé de l'enseignement, qu'il s'agisse de 
réfléchir sur "Culture scolaire, pédagogies et politique », sur "Les disciplines et le choix des normes ", sur "Démocratisation et critique des hiérarchies", ou encore de débattre autour d'Antoine Prost (sur l'école républicaine), d'Alain Renaut (sur le problème de l'autorité) ou de Marcel Gauchet (sur les rapports entre culture, enseignement et société).

Il ne pouvait toutefois être question ici de discuter en détail des contributions ressortissant à des disciplines très diverses. On se limitera donc à celles qui relèvent de l'histoire stricto sensu, que réunit la première partie. Trois d'entre elles sont référées à une époque précise - celle qui décrit le programme et la pédagogie des écoles philosophiques de l'Antiquité (Philippe Hoffmann, p.13-44), celle qui montre la prégnance du modèle scolaire chez les clercs médiévaux, à travers l'analyse d'un sermon de Robert de Sorbon où l'entrée au paradis est vue comme une sorte d'examen (Jean-Luc Solère, p. 45-64) et celle qui traite des incertitudes présentes sur la mission de l'école (François Jacquet-Francillon, p. 103-113) - tandis que trois autres, axées sur des problématiques précises, embrassent des durées plus longues: Marie-Madeleine Compère étudie le passage des humanités à la "culture générale » (p.65-76), André Chervel se penche sur les diverses réponses qu'on peut apporter à la question de savoir ce que signifie l'expression «culture scolaire » (p. 77-85) et Françoise Waquet met en évidence la place de l'oralité dans cette culture (p. 87-102). Ainsi, ce volume permet au non-spécialiste d'accéder, sous une forme abrégée commode, à des travaux d'histoire de l'éducation qu'il n'a pas forcément eu le temps ou l'occasion de connaître.

\section{AUTEURS}

\section{ANNIE BRUTER}

